\title{
Modelling and studies of the spectral response of some optoelectronic components
}

\author{
André Albino ${ }^{* a, b}$, Daniele Bortoli ${ }^{\mathrm{a}, \mathrm{b}}$, Mouhaydine Tlemçani ${ }^{\mathrm{a}, \mathrm{b}}$, António Joyce ${ }^{\mathrm{c}}$ \\ ${ }^{a}$ University of Évora, Physic Department, Colégio Luís António Verney, Rua Romão Ramalho 59, \\ 7000-671 Évora, Portugal; \\ ${ }^{\mathrm{b}}$ Institute of Earth Sciences, Rua Romão Ramalho 59, 7000-671 Évora, Portugal; \\ ${ }^{c}$ Nacional Laboratory of Energy and Geology, Energy Laboratory, Solar Energy Unit, Estrada do \\ Paço do Lumiar 20, Lisboa, 1649-039 Lisboa, Portugal
}

\begin{abstract}
Solar radiation takes in today's world, an increasing importance. Different devices are used to carry out spectral and integrated measurements of solar radiation. Thus the sensors can be divided into the fallow types: Calorimetric, Thermomechanical, Thermoelectric and Photoelectric. The first three categories are based on components converting the radiation to temperature (or heat) and then into electrical quantity. On the other hand, the photoelectric sensors are based on semiconductor or optoelectronic elements that when irradiated change their impedance or generate a measurable electric signal. The response function of the sensor element depends not only on the intensity of the radiation but also on its wavelengths. The radiation sensors most widely used fit in the first categories, but thanks to the reduction in manufacturing costs and to the increased integration of electronic systems, the use of the photoelectric-type sensors became more interesting.

In this work we present a study of the behavior of different optoelectronic sensor elements. It is intended to verify the static response of the elements to the incident radiation. We study the optoelectronic elements using mathematical models that best fit their response as a function of wavelength. As an input to the model, the solar radiation values are generated with a radiative transfer model. We present a modeling of the spectral response sensors of other types in order to compare the behavior of optoelectronic elements with other sensors currently in use.
\end{abstract}

Keywords: Solar radiation spectrum, Optoelectronics, Transfer functions, Solar radiation sensors

\section{INTRODUCTION}

\subsection{Solar Radiation}

Since ancient time solar radiation plays a key role in the mankind live and welfare: source of heat and light as well as its importance in agriculture and sustainability. Anyway also in the past the radiation was utilized as weapon against the enemies (Archimedes in Syracuse) ${ }^{1}$. Solar radiation can be divided into three types, global, direct and diffuse. Each type of radiation differs only in the way the radiation hits the ground (or sensor), so the global radiation is any solar radiation which reaches the sensor, the direct one, as the name indicates, is the radiation that reaches the sensor directly from the sun and finally the diffuse radiation is the radiation that reaches the sensor after been scattered in the atmosphere. Differentiating the three types of radiation is important for different applications, such as some solar technologies that only use the direct radiation and the use of direct solar radiation for estimating the composition of the atmosphere. ${ }^{1,2}$

*aalbino@uevora.pt;

Earth Resources and Environmental Remote Sensing/GIS Applications VII, edited by Ulrich Michel, Karsten Schulz,

Manfred Ehlers, Konstantinos G. Nikolakopoulos, Daniel Civco, Proc. of SPIE Vol. 10005, 1000505

(C) 2016 SPIE · CCC code: 0277-786X/16/\$18 · doi: 10.1117/12.2242024 
Beyond the differentiation by type it is important to realize that to better use solar radiation it is necessary to understand the solar radiation spectrum. The spectrum in defined condition (no clouds, fixed solar height, fixed weather ...) has been described in references, for example, by the American Society for Testing and Materials ${ }^{3}$ or by World Radiation Center ${ }^{4}$.

The solar spectrum interacts with different receivers whether natural or applications created by man as photovoltaic cells. These receptors have an absorption spectrum defined, for example, the absorption of a one leaf in the process of photosynthesis is different from the absorption of different technologies used in photovoltaic conversion, as can be seen in figure $1^{5}$. Due to different absorptions in it receivers becomes important to better understand the solar spectrum at each location.

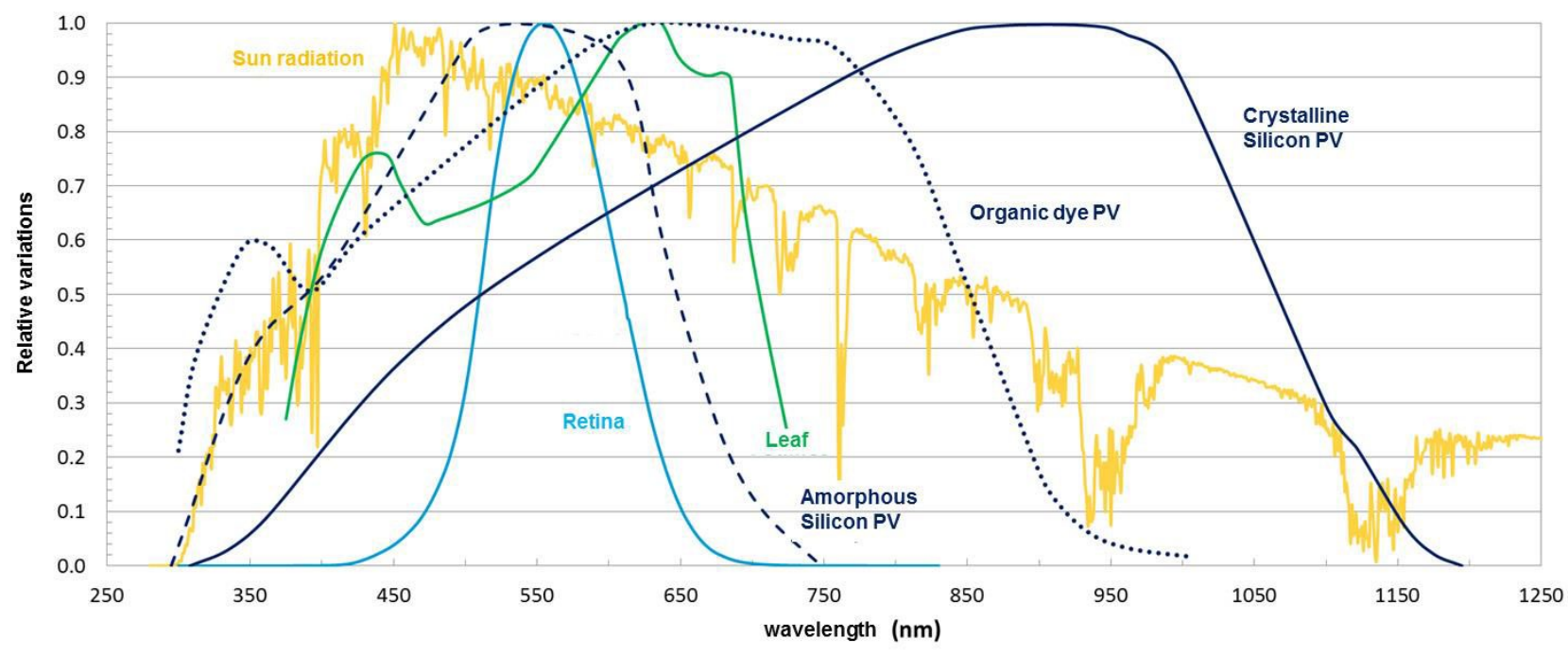

Figure 1. Typical solar spectrum and some transfers functions ${ }^{5}$.

\subsection{Solar radiation Sensors}

The solar radiation measurement sensors can be divided by their transduction principle: thermoelectric, calorimetric, thermomechanical or photoelectric. The most current sensors work with calorimetric transducers, that is, by converting solar radiation into heat and then heat into measurable electrical signal. These sensors register an integrated value of solar radiation, can't take the same information about spectrum and different values for specific applications. These sensors present prices in the range of a few hundred euros.

Another way to measure the solar radiation is through spectroradiometers, these devices make it possible to measure, as the name indicates, the radiation spectral shape. The spectroradiometers are more difficult to use and more complex than the sensors previously presented. The price of spectroradiometers can reach a few thousand euros.

In the last twenty years there have been advances in electronics, more specifically in optoelectronics. This advances took to the reduction of components and optimization of their functional characteristics, such as reduction of cost, among others. With these developments became easier and cheaper to setup sensors with photoelectric principle, for example, SP Lite2 of the Kipp \& Zonen ${ }^{6}$. These advances will allows for the creation of new measuring instruments either integrated solar radiation or spectral solar radiation. 
In this work we propose to simulate the response of some optoelectronic components when exposed to solar radiation. Such components are characterized according to their spectral transfer function and compared with current sensors.

\section{ELECTRONIC DEVICES AND SENSORS}

The components selected for the simulations are optoelectronic components: photodiodes, phototransistors and photosensitive integrated circuits. The photodiodes are semiconductors capable of converting light into electric current through the photoelectric effect. On the other hand, phototransistors are usually bipolar transistors where the base collector junction can be active by the external radiation generating an electric current. The photosensitive integrated circuits are electronic circuits with photodiodes, phototransistors, amplifiers, among others.

The components used in this study are presented in table 1.

\subsection{Components used}

Table 1. Table with information about optoelectronic components used

\begin{tabular}{|cccc|}
\hline Model & Fabricant & Type & Reference \\
\hline LV0101CF & SANYO & & 7 \\
S6809 & HAMAMATSU & photo IC & 8 \\
S6986 & HAMAMATSU & & 8 \\
\hline HP-3ML & KODENSHI & & 9 \\
HP-3MLR2 & KODENSHI & & 9 \\
HP-5FR4 & KODENSHI & & 10 \\
S11499 & HAMAMATSU & & 11 \\
S1226 & HAMAMATSU & photodiode & 11 \\
S1227 & HAMAMATSU & & 11 \\
S1336 & HAMAMATSU & & 11 \\
S1337 & HAMAMATSU & & 11 \\
S3590 & HAMAMATSU & & 11 \\
S9219 & HAMAMATSU & & 11 \\
\hline MTD6140 & MARKTECH & & 13 \\
MTD8060P & MARKTECH & phototransistor & 13 \\
ST-1KL3A & KODENSHI & & \\
TPS611 & TOSHIBA & & \\
\hline
\end{tabular}

The feature of the optoelectronic devices analysed was the spectral response and was obtained from their datasheets using the tool WebPlotDigitizer ${ }^{16}$. In figure 2 some examples of the obtained transfer functions are presented. All datasheets have the spectral response of components under STP conditions. 


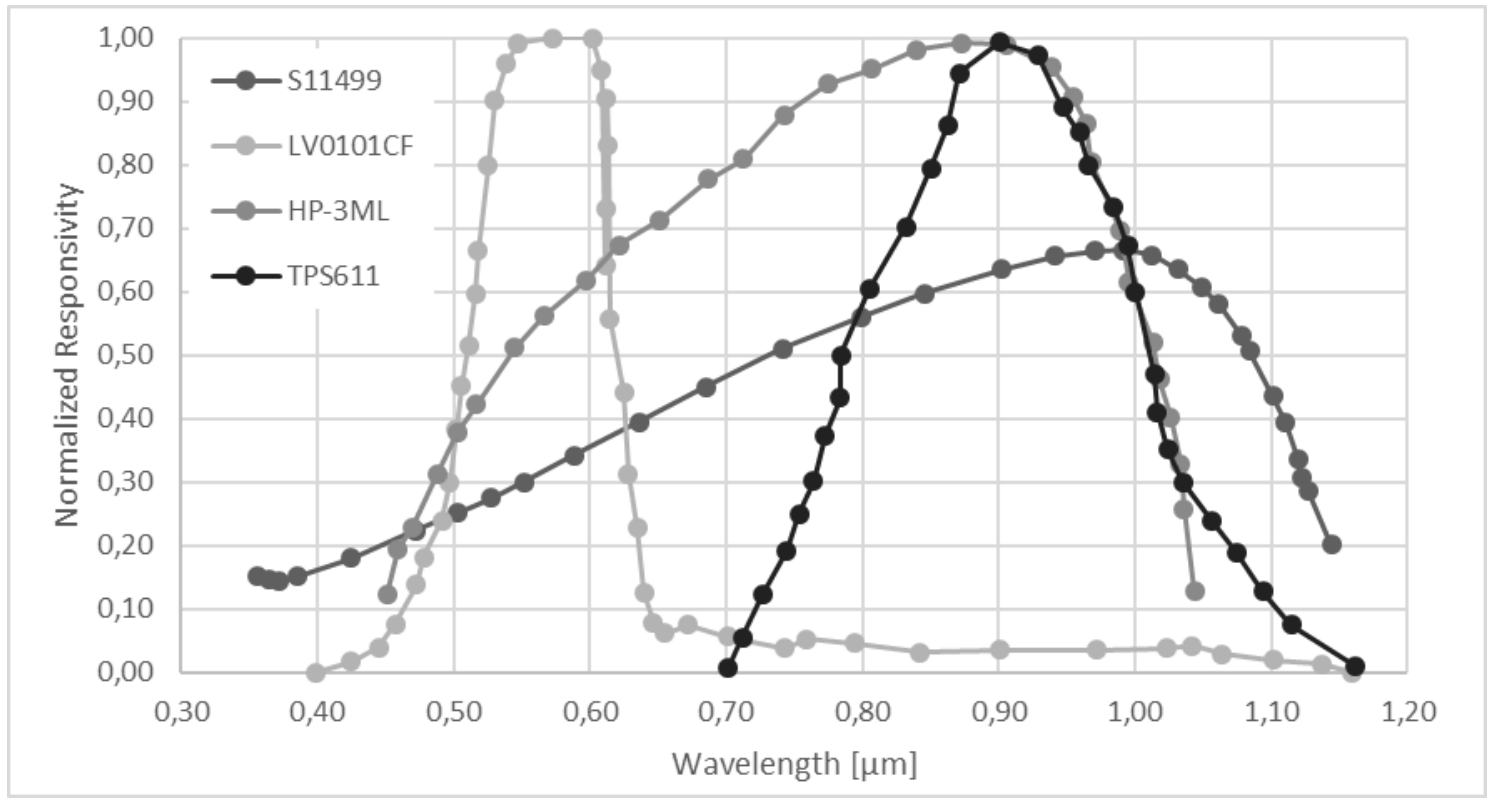

Figure 2. Transfer functions of some sensors

\subsection{Sensors used}

The instruments used for comparison were a CM6B ${ }^{17}$ and CHP $1{ }^{18}$, both manufactured by Kipp \& Zonen. These sensors are well classified according to ISO 9060 and have been chosen because they are widely used by researchers as well as by companies. Also for the instrument their spectral responses were obtained from the respective datasheet with application of WebPlotDigitizer ${ }^{16 .}$

According to ISO 9060 the CM6B sensor is a first-class instrument. This instrument is used to measure the irradiance on a plane, and can measure global solar radiation or diffuse solar radiation. To measure the diffuse solar radiation is essential the use of a shadow band allowing to hide the sun. The CM6B operates according to the thermoelectric principle and it is made by 64 thermocouples. This instrument is non-selective to the spectral radiation, it absorbs all radiation incident on the sensor between 0,310 and 2,800 micrometre.

On the other hand, the CHP 1 is a first class pyrheliometre able to measure irradiance with a field of view of $5^{\circ}$. This instrument is also based on the thermoelectric principle absorbs 97 to $98 \%$ of the radiation incident on the sensor.

\section{SIMULATION}

We simulate solar radiation spectrum for a fixed condition, considering an ambient temperature of $25^{\circ} \mathrm{C}$. In figure 3 the global, direct and diffuse solar radiation spectra are presented. 


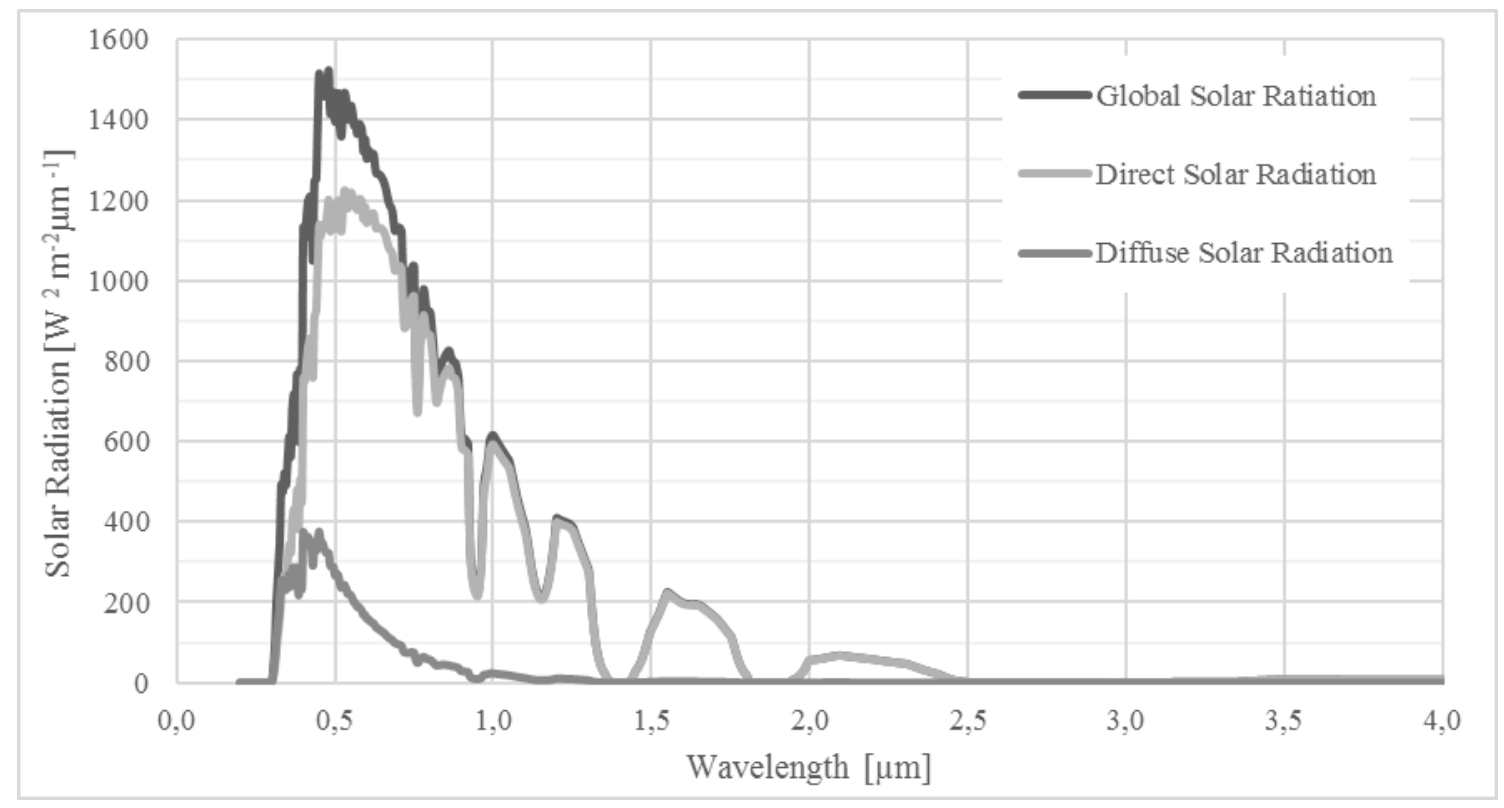

Figure 3. Simulated solar radiation spectra.

With the spectra of solar radiation and the sensor and equipment transfer functions we calculate the spectral radiative response from each of the sensors and equipment and for each radiation, global, direct and diffuse. Example of simulated radiation for the sensors shown in figure 2 are presented in figures 4,5 and 6.

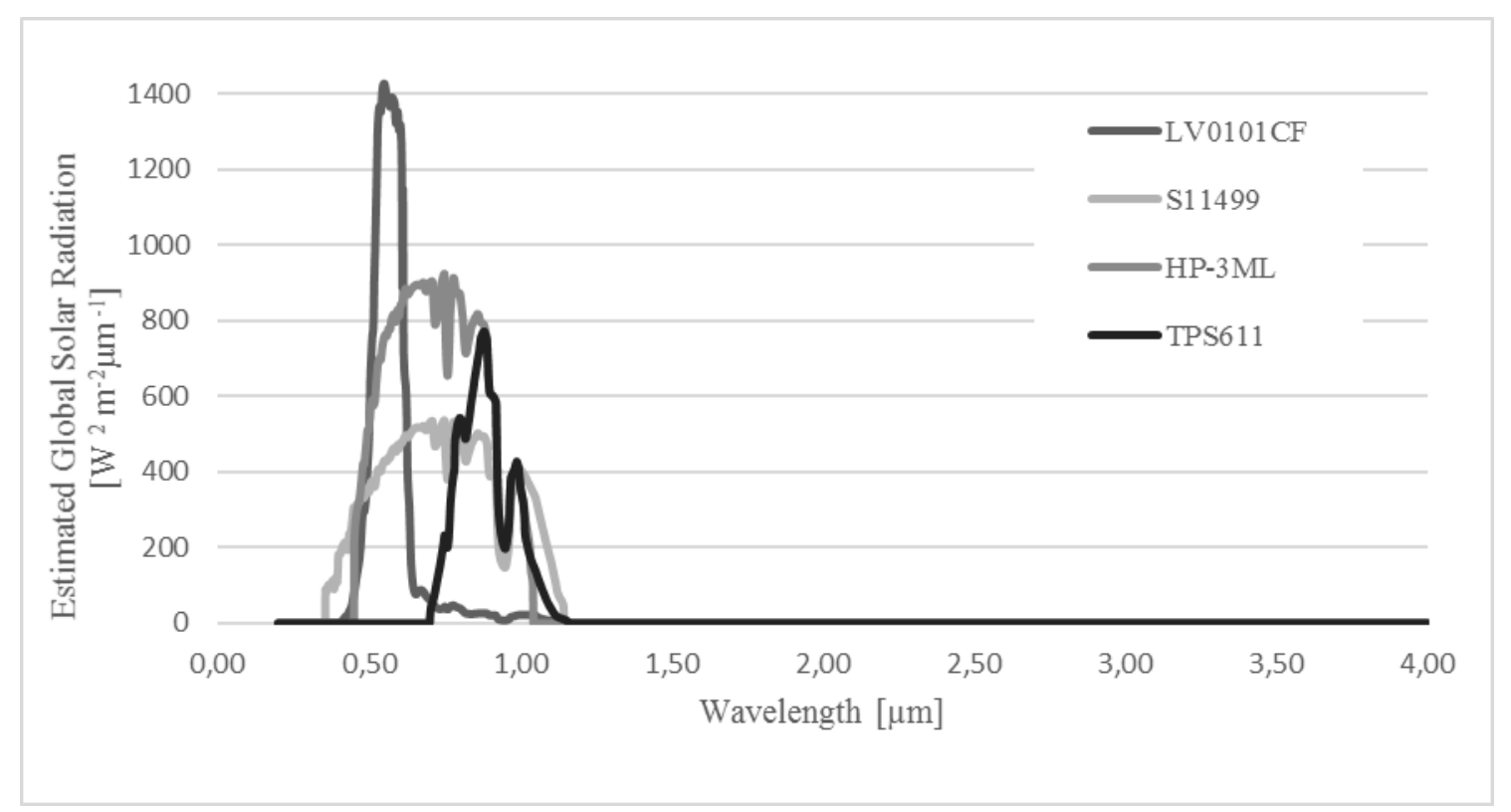

Figure 4. Estimated global solar radiation of some sensors 


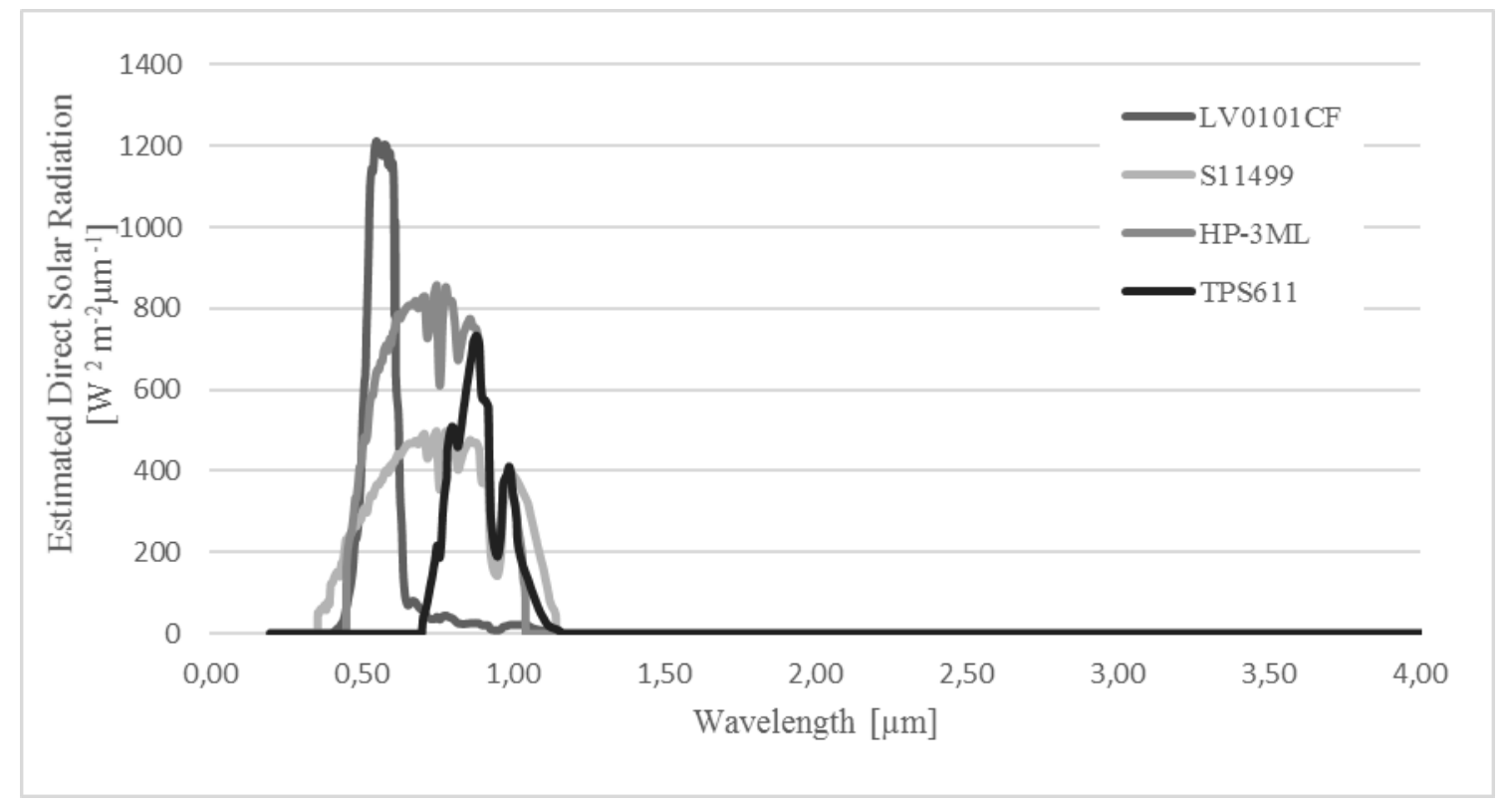

Figure 5. Estimated direct solar radiation of some sensors.

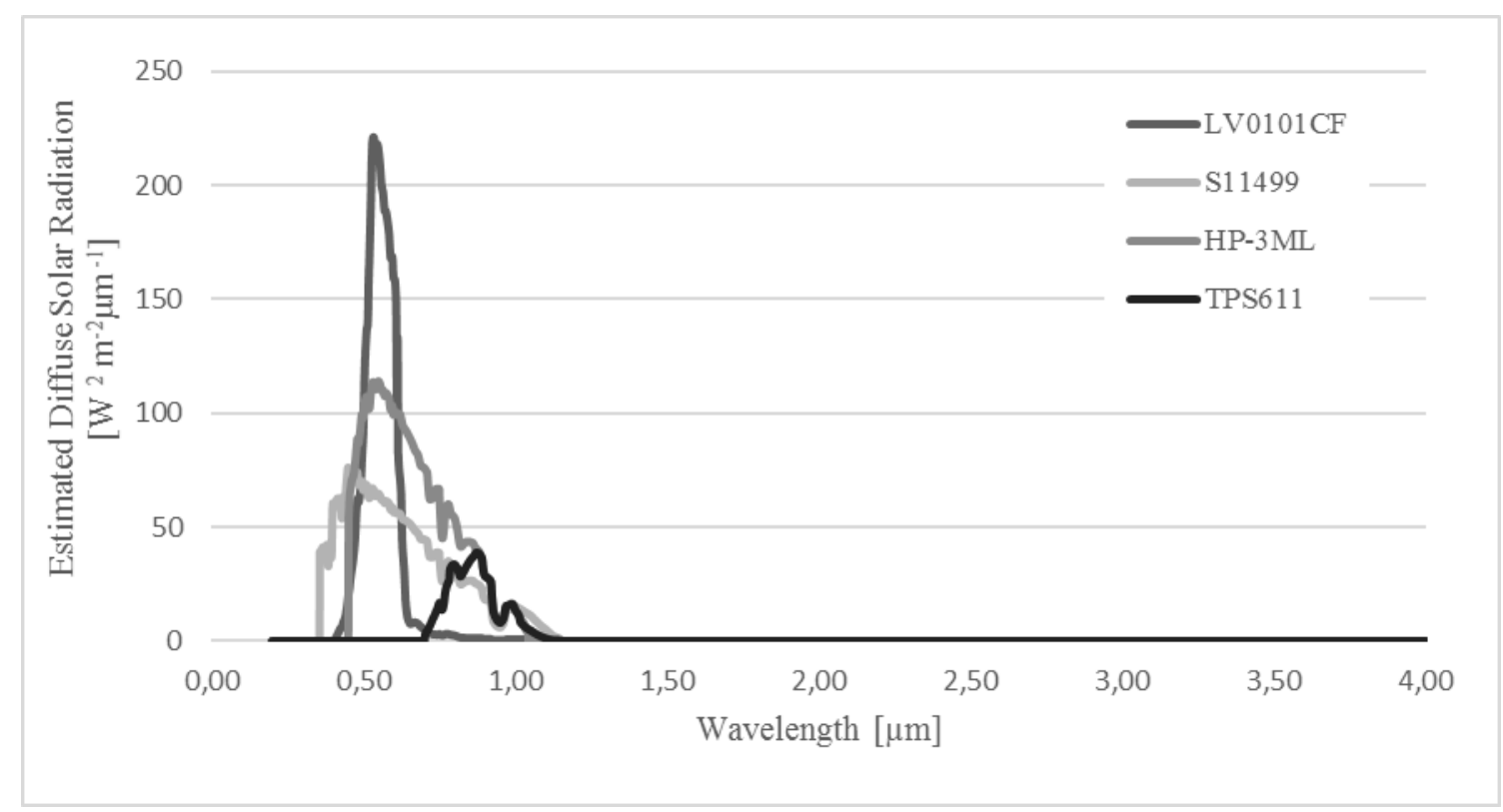

Figure 6. Estimated diffuse solar radiation of some sensors. 


\section{COMPARISON AND RESULTS}

To compare the different sensors, we effected partial integration for the three main regions of the solar spectrum, ultraviolet (UV;100-400nm), visible (VIS; 380-760nm) and infrared (IR; > 760nm) ${ }^{19}$. We have done a comparison between radiation intercepted by sensor and the total available radiation. In figure 7 we can see that, as expected, the CM6B instrument absorb almost all of the global solar radiation. Of all sensors tested we highlight HP-3ML, HP-5FR4, LV0101CF and S3590. In the case of direct solar radiation, figure 8, the instrument currently use - CHP1 - absorbed nearly $100 \%$ of the radiation, while the sensors we highlighted HP-5FR4, LV0101CF, MTD8060P and S6986. Finally, the simulation with the diffuse radiation, stand out HP-3MLR2, LV0101CF, S3590 and S6986 sensors, present in figure 9.

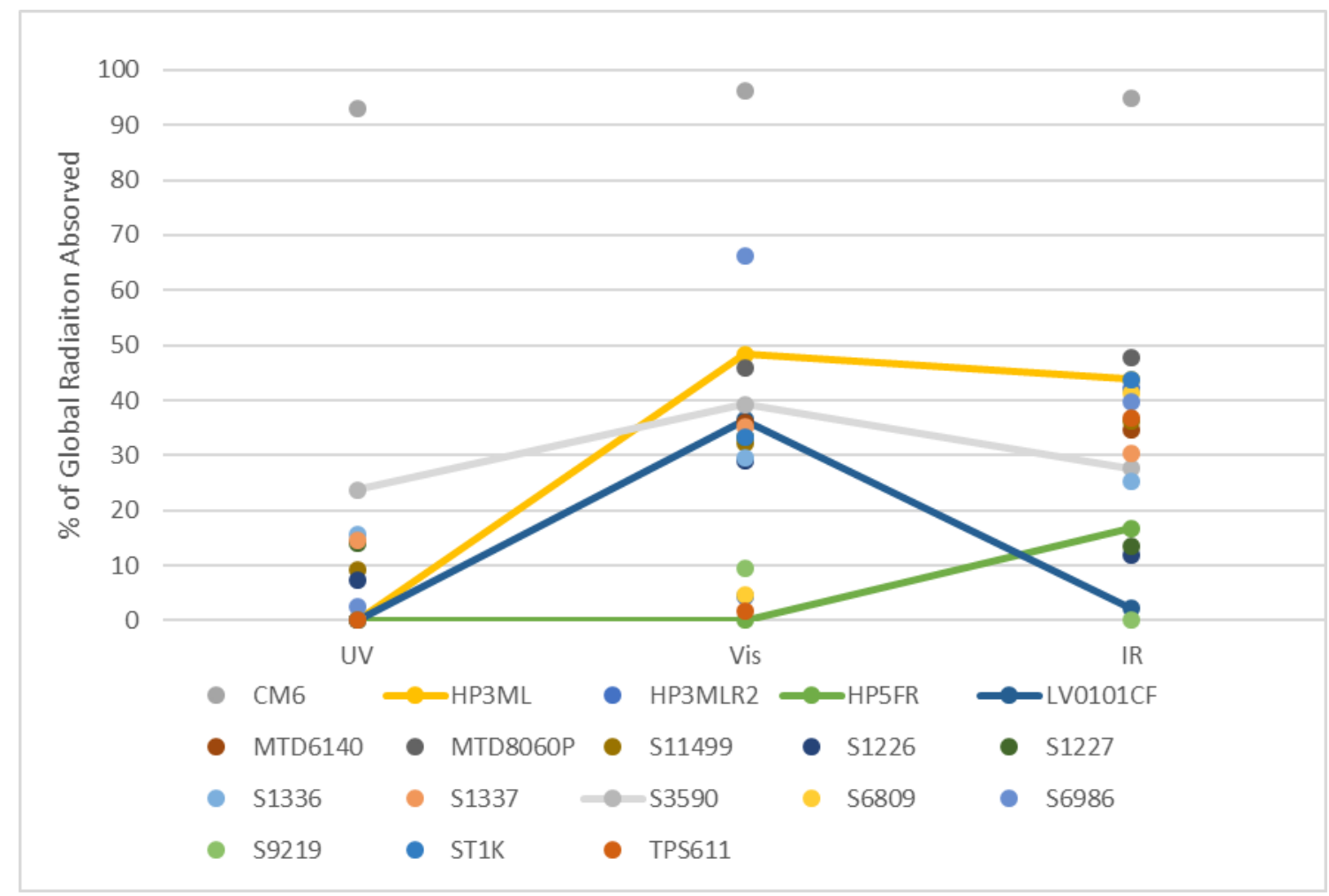

Figure 7. Comparison of sensors using global solar radiation. 


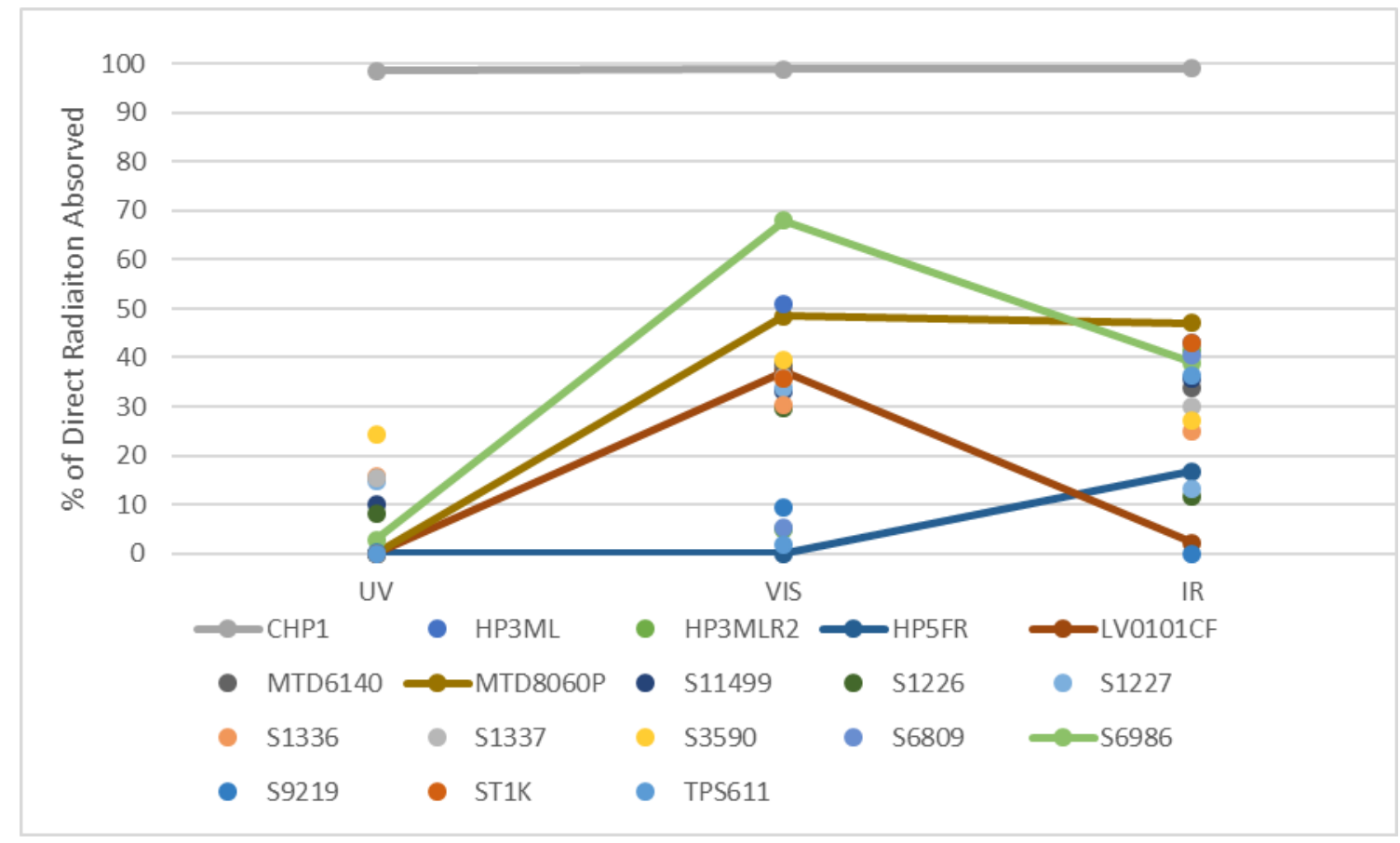

Figure 8. Comparison of sensors using direct solar radiation.

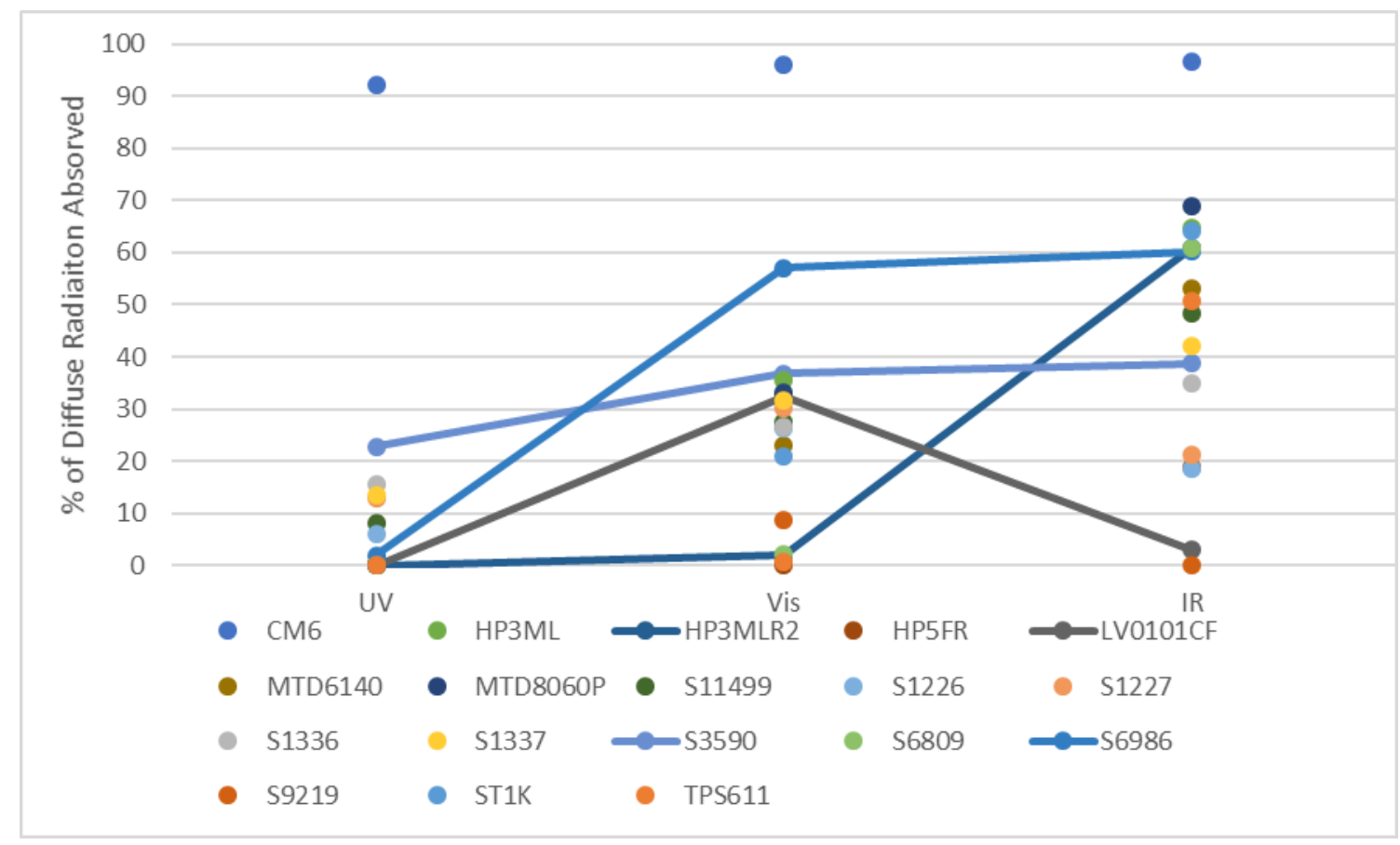

Figure 9. Comparison of sensors using diffuse solar radiation.

Proc. of SPIE Vol. 10005 1000505-8 
The selected sensors have characteristics indicating the possibility to measure the solar radiation in total or in specific spectral bands. To allow to for the development and the setup of a new radiation detector, more laboratory tests are necessary, in order to better characterize other features of the selects electronic components, such as noise, temperature dependencies and angular sensitivity.

\section{ACKNOWLEDGMENT}

The first author gratefully acknowledges the financial support of "Fundação para a Ciência e Tecnologia" (FCT Portugal), through the Doctoral Grant SFRH/BD/108484/2015.

The work is co-funded by the European Union through the European Regional Development Fund, included in the COMPETE 2020 (Operational Program Competitiveness and Internationalization) through the ICT project (UID / GEO / 04683/2013) with the reference POCI-01-0145-FEDER-432 007690.

\section{REFERENCES}

[1] Albino, A., Tlemçani, M. and Salgado, R., "Radiação solar: estudo e criação de plataforma de apoio à conceção de um sensor de radiação solar," Msc Thesis, University of Évora, Portugal(2014).

[2] Antón, M., Bortoli, D., Vilaplana, J.M., Silva, A.M., Serrano, A., Costa, M.J., de la Morena, B. and Kroon, M., "Total ozone column from direct and diffuse spectral solar irradiance in the Southwest of the Iberian peninsula," Journal of Geophysical Research-Atmosphere, 115, doi:10.1029/2009JD012514 (2010)

[3] Standard Tables for Reference Solar Spectral Irradiances: Direct Normal and Hemispherical on $37^{\circ}$ Tilted Surface. ASTM G173 - 03; 2008

[4] Wehrli, C. "Extraterrestrial Solar Spectrum," Publication no. 615, Physikalisch-Meteorologisches Observatorium + World Radiation Center (PMO/WRC) Davos Dorf, Switzerland, July 1985.

[5] Tourasse,G. and Dumortier,D., "Development of a system measuring the solar radiationspectrum in 5 planes for daylight and PV applications," Energy Procedia 57, 1110 - 1119 (2014).

[6] SP-LITE Silicon Pyranometer, Instruction Manual Campbell Scientific (2004).

[7] LV0111 Datasheet, SANYO Semicondutors (2011).

[8] Light modulation photo IC S4282-51, S6809, S6846, S6986, S7136/-10, S10053, Hamamatsu Photonics (2007).

[9] HP - 3ML, HP - 3MLR2 Datasheet, Kodenshi.

[10] HP - 5FR4, HP - 5FR3 Datasheet, Kodenshi.

[11] Si Photodiodes Selection guide, Hamamatsu Photonics (2014).

[12] MTD6140 Datasheet, Marktech Optoelectronics.

[13] MTD8060P Datasheet, Marktech Optoelectronics.

[14] ST- 1KL3A, ST- 1KL3B Datasheet, Kodenshi.

[15] TPS611 Datasheet, Toshiba (2007).

[16] Rohatgi, A., "WebPlotDigitalizer" version 3.1 May 2016, http://arohatgi.info/WebPlotDigitizer (July 2016).

[17] CM6B Pyranometer / CM7B Albedometer Instruction Manual, Kipp\&Zonen (2003).

[18] CHP1 Pyrheliometer Instruction Manual, Kipp\&Zonen (2008).

[19] ISO 21348, "Space environment (natural and artificial) — Process for determining solar irradiances," Standard 2007. 